\title{
JNPH
}

Volume 5 No. 2 (Desember 2017)

(C) The Author(s) 2017

\section{APLIKASI TEORI MODEL IMOGENE KING TENTANG MOTIVASI KESEMBUHAN DENGAN KEPATUHAN MINUM OBAT TB PARU PADA TN. J DI KELURAHAN KANDANG RT. 06 DI WILAYAH KERJA PUSKESMAS KANDANG KOTA BENGKULU}

\author{
THE IMPLEMENTATION OF THE THEORY IN IMOGENE KING MODEL ABOUT \\ HEALTH MOTIVATION WITH COMMON DRUG DRILL IN TN. A IN KANDANG \\ RT. 06 IN WORKING AREA OF KANDANG PUBLIC HEALTH CENTER \\ BENGKULU CITY
}

\author{
HEVVI MILYA \\ UPTD PUSKESMAS KANDANG KOTA BENGKULU \\ Email: hevvi85@yahoo.coid
}

\begin{abstract}
ABSTRAK
Kepatuhan minum obat merupakan salah satu indikator penting dalam keberhasilan pengobatan suatu penyakit. TB merupakan salah satu penyakit yang memerlukan pengobatan yang lama, untuk itu diperlukan suatu pendekatan interaksi dengan pasien, untuk proses pengobatan. Salah satu teori keperawatan yang dapat digunakan adalah teori King memahami model konsep dan teori keperawatan dengan menggunakan pendekatan system terbuka dalam hubungan interaksi yang konstan dengan lingkungan, sehingga King mengemukakan dalam model konsep interaksi. Tujuan penelitian untuk menerapkan aplikasi model keperawatan dari teori model Imogene King dan penerapannya pada asuhan keperawatan pada Tn. J. Dalam penelitian ini penulis akan mengurai laporan kasus/asuhan keperawatan yang diberikan pada Tn. J dengan mengaplikasikan teori model Imogene King yang dilaksanakan selama 1 minggu pada tanggal 15-20 Mei 2017 dengan menggunakan metode proses keperawatan yang meliputi pengkajian, diagnose keperawatan, perencanaan, implementasi dan evaluasi asuhan keperawatan ini. Hasil penelitian ini didapatkan bahwa teori Imigene King cocok diaplikasikan pada pasien dengan TB. Diharapkan penelitian ini dapat dijadikan sebagai sumber informasi dan kumpulan materi tentang perilaku Penderita TB Paru terhadap kepatuhan dalam hal minum obat sehingga motivasi kesembuhannya terus ada dan dapat mencegah resiko penularan penyakit TB Paru kepada anggota keluarga lainnya, serta dapat dijadikan objek penelitian lainnya dari aspek dan sudut pandang yang berbeda.
\end{abstract}

Kata Kunci: Imigene King, TB, motivasi minum obat

\begin{abstract}
Drug adherence is one of the important indicators in the successful treatment of a disease. TB is one of the diseases that require long treatment, for that needed an approach of interaction with the patient, for the treatment process. One of the theories of nursing that can be used is King's theory of understanding the concept model and the theory of nursing by using an open system approach in a constant interaction with the environment, so King put forward in the concept of interaction model. The objective of the study was to apply the nursing model application from
\end{abstract}


the Imogene King Model Theory and its application to nursing care at Tn. J. In this study the authors will parse the case report / nursing care given on Mr. J by applying Imogene King model theory which is implemented for 1 week on 15-20 May 2017 by using nursing process method which includes assessment, nursing diagnosis, planning, implementation and evaluation of this nursing care. The results of this study found that Imogene King theory is suitable to be applied in patients with TB. It is expected that this research can be used as a source of information and a collection of material about the behavior of lung tuberculosis patients to adherence in terms of taking medicine so that the healing motivation continues to exist and can prevent the risk of transmission of pulmonary TB disease to other family members, and can be used as other research object from the aspect and angle different view.

\section{Keywords: imogene king, TB, motivation drinking drugs}

\section{PENDAHULUAN}

Tujuan pembangunan kesehatan menuju Indonesia Sehat 2025 adalah meningkatnya kesadaran, kemauan, dan kemampuan hidup sehat bagi setiap orang agar peningkatan derajat kesehatan masyarakat yang setinggitingginya dapat terwujud, melalui terciptanya masyarakat, bangsa dan negara Indonesia yang sehat. Pencapaian tujuan pembangunan kesehatan tersebut pada masyarakat yang diharapkan adalah perilaku yang bersifat proaktif untuk memelihara dan meningkatkan kesehatan, mencegah resiko terjadinya penyakit, melindungi diri dari ancaman penyakit (Depkes, 2009).

Menurut World Health Organization (WHO) melaporkan prevalensi terjadinya kasus TBC di wilayah Asia Tenggara sebesar 5 juta dan kasus TBC di Indonesia sebanyak 3,5juta. Di Indonesia yang berpenduduk sekitar 240 juta memiliki jumlah TBC yang tinggi dan masuk kedalam urutan empat tertinggi secara global. Diperkirakan prevalensi dan kejadian TBC pada tahun 2010 adalah 286 keluarga dan 189 orang yang berpositif TBC untuk setiap 100.000 populasi (Syamsudin, 2013).

Indonesia termasuk dalam high burden countries, menempati urutan keempat setelah India, China dan Afrika Selatan. Jumlah penderita TB Paru BTA positif di Indonesia secara nasional pada tahun 2005 adalah sebesar 158.640 orang. Sedangkan tahun 2008 angka penderita TB Paru BTA positif mengalami sedikit peningkatan menjadi sebesar 161.741 kasus (Depkes RI, 2009).
Penurunan angka kesakitan dan kematian akibat penyakit TBC terus dilakukan oleh pemerintah Republik Indonesia diseluruh provinsi di Indonesia, namun kejadian TBC masih saja tetap tinggi, salah satunya terdapat di provinsi Bengkulu berdasarkan laporan tahunan TBC pada tahun 2010 kasus TBC berjumlah 1502 orang, tahun 2011 berjumlah 1614 orang, dan tahun 2012 berjumlah 1770 orang (Dinkes Provinsi bengkulu, 2012). Tuberkulosis Paru merupakan suatu penyakit yang disebabkan oleh Mycobacterium tuberculosis dan dapat hadir dalam bentuk laten maupun aktif. Penyakit ini menular melalui udara dan terutama mempengaruhi orang dewasa muda yang produktif (Syamsudin, 2013).

Secara umum, penyakit Tuberkulosis paru merupakan penyakit infeksi yang masih menjadi masalah kesehatan dalam masyarakat kita. Penyakit Tuberkulosis paru (TB) dimulai dari Tuberkulosis yang berarti suatu penyakit infeksi yang disebabkan bakteri berbentuk batang dikenal dengan nama Mycobacteruim tuberkulosis. Penularan penyakit ini melalui perantara ludah atau dahak penderita yang mengandung basil tuberkulosis paru pada saat penderita batuk, butiran air ludah berterbangan di udara dan terhisap oleh orang sehat sehingga masuk kedalam paru-parunya, yang kemudian menyebabkan penyakit tuberkulosis paru (Naga, S 2014). TB Paru merupakan salah satu penyakit menular yang masih menjadi permasalahan di dunia hingga saat ini, tidak hanya di negara berkembang tetapi juga di negara maju. WHO memperkirakan sepertiga penduduk dunia 
telah terinfeksi oleh TB Paru. Hal ini dibuktikan dengan masih banyaknya jumlah penderita TB Paru yang ditemukan di masyarakat dan sejak tahun 1993, WHO menyatakan bahwa TB Paru merupakan kedaruratan global bagi kemanusiaanTuberkulosis (TB) merupakan penyakit yang sangat banyak didapatkan di negara yang sedang berkembang, baik pada anak maupun orang dewasa yang juga dapat menjadi sumber infeksi. sekitar 500.000 anak di dunia menderita Tuberkulosis (TB) setiap tahun. Word Health Organization (WHO) mengestimasikan kasus Tuberkulosis (TB) anak di tahun 2012 kurang lebih 530.000 kasus atau sekitar $6 \%$ dari total kejadian Tuberkulosis dan 74.000 anak meninggal akibat Tuberkulosis (TB) setiap tahunnya (WHO, 2013).

Angka insidensi semua tipe TB Paru Indonesia tahun 2012 adalah 450.000 kasus atau 189 per 100.000 penduduk, angka prevalensi semua tipe TB Paru 690.000 atau 289 per 100.000 penduduk dan angka kematian TB Paru 64.000 atau 27 per 100.000 penduduk atau 175 orang per hari. Meskipun memiliki beban penyakit TB Paru yang tinggi, Indonesia merupakan negara pertama diantara High Burden Country (HBC) di wilayah WHO South-East Asian yang mampu mencapai target global TB Paru untuk deteksi kasus dan keberhasilan pengobatan pada tahun 2006. Tahun 2009, tercatat sejumlah sejumlah 294.732 kasus TB Paru telah ditemukan dan diobati (data awal Mei 2010) dan lebih dari 169.213 diantaranya terdeteksi BTA + , dengan demikian, Case Notification Rate untuk TB Paru BTA+ adalah 73 per 100.000 penderita TB Paru yang diperiksa. Rerata pencapaian angka keberhasilan pengobatan selama 4 tahun terakhir adalah sekitar 90\% dan pada kohort tahun 2008 mencapai $91 \%$.

Angka kejadian Tuberkulosis (TB) di Indonesia pada tahun 2013 sebanyak 7,92\% sedangkan pada tahun 2014 terjadi penurunan yaitu 7,10\%, dan tahun 2015 terjadi peningkatan sebanyak 8,59\% berdasarkan karakteristiknya semakin tinggi kelompok umur semakin tinggi pula prevalensi TB paru, akan tetapi untuk kelompok umur 1 sampai 4 tahun mempunyai prevelensi yang cukup tinggi yaitu $0,4 \%$ dan $0,2 \%$ pada kelompok umur kurang dari 1 tahun (Kemenkes RI,2016). Di Indonesia, prevalensi TB paru dikelompokkan dalam tiga wilayah, yaitu wilayah Sumatera (33\%), wilayah Jawa dan Bali (23\%), serta wilayah Indonesia Bagian Timur (44\%) (Depkes, 2011). Penyakit TB paru merupakan penyebab kematian nomor tiga setelah penyakit jantung dan saluran pernafasan pada semua kelompok usia serta nomor satu untuk golongan penyakit infeksi. Korban meninggal akibat TB paru di Indonesia diperkirakan sebanyak 61.000 kematian tiap tahunnya (Depkes RI, 2011).

Tingginya angka kejadian TB paru di seluruh dunia sering terjadi karena kepatuhan pasien dalam pengobatan yang rendah $(45 \%)$ (Viney, 2011). Kepatuhan minum obat merupakan salah satu indikator penting dalam keberhasilan pengobatan suatu penyakit.Kepatuhan rata-rata pasien pada pengobatan jangka panjang terhadap penyakit kronis sangat bervariasi.Di negara maju persentase kepatuhan pasien minum obat adalah sebesar 50\% sedangkan untuk negara berkembang persentase hanya sekitar $24 \%$ (WHO, 2003).

Kepatuhan pasien yang rendah dalam minum obat merupakan masalah kesehatan yang serius dan hal ini sering terjadi ketika pasien dihadapi dengan pengobatan jangka panjang terhadap penyakit kronis yang dialaminya seperti penyakit TB paru (Depkes RI, 2005). Rendahnya kepatuhan minum obat pada pasien TB paru akan memperlambat proses penyembuhan penyakit, meningkatkan risiko morbiditas, mortalitas, dan resistensi obat baik terhadap satu jenis OAT (mono resistant), maupun lebih dari satu jenis OAT (poly resistant, multidrug resistant, extenly drug resistant, atau totally drug resistant) (BPOM RI, 2006). Kepatuhan pasien yang rendah dalam minum OAT juga menyebabkan pasien menjadi sumber penularan kuman yang resisten di masyarakat, hal ini tentunya akan mempersulit pemberantasan penyakit 
TB paru di Indonesia serta memperberat beban pemerintah (Depkes RI, 2005).

Kepatuhan minum obat dipengaruhi oleh beberapa faktor seperti pengetahuan dan sikap (BPOM RI, 2006). Menurut penelitian Tachfouti et al (2011) terdapat hubungan nyata antara pengetahuan dan sikap dengan kepatuhan minum obat anti tuberkulosis di Morocco, Afrika. Menurut penelitian Avianty (2005) pengetahuan dan sikap menjadi faktor yang mempengaruhi tingkat kepatuhan seseorang dalam minum obat. Menurut penelitian Luluk di Puskesmas Gatak Surakarta (2012) dikatakan bahwa ada hubungan yang signifikan antara pengetahuan terhadap kepatuhan minum obat pasien TB Paru. Keberhasilan pengobatan tuberculosis tergantung pada pengetahuan pasien dan dukungan dari keluarga. Tidak ada upaya dari diri sendiri atau motivasi dari keluarga yang kurang memberikan dukungan untuk berobat secara tuntas akan mempengaruhi kepatuhan pasien untuk mengkonsumsi obat. Apabila ini dibiarkan, dampak yang akan muncul jika penderita berhenti minum obat adalah munculnya kuman tuberculosis yang resisten terhadap obat, jika ini terus terjadi dan kuman tersebut terus menyebar pengendalian obat tuberculosis akan semakin sulit dilaksanakan dan meningkatnya angka kematian terus bertambah akibat penyakit tuberculosis (Indan Enjang, 2011).

\section{METODE PENELITIAN}

Dalam penelitian ini penulis akan mengurai laporan kasus/asuhan keperawatan yang diberikan pada Tn. J dengan mengaplikasikan teori model Imogene King yang dilaksanakan selama 1 minggu pada tanggal 15-20 Mei 2017 dengan menggunakan metode proses keperawatan yang meliputi pengkajian, diagnose keperawatan, perencanaan, implementasi dan evaluasi asuhan keperawatan ini.

\section{HASIL PENELITIAN}

Pada bab ini akan dibahas mengenai pelaksanaan asuhan keperawatan pada An.S dengan penyakit Hydrochepalus di Jl Padat Karya Rt.01 Kel. Sumur Dewa Kota Bengkulu. Dilakukan melalui beberapa proses keperawatan yang terdiri dari pengkajian, analisis data, diagnosa, intervensi, implementasi, dan evaluasi.

\section{Tahap Pengkajian}

Menurut King, pengumpulan data klien yaitu nama, umur, jenis kelamin, pendidikan, suku, obat-obatan, status sosial dan riwayat diet. Pengkajian yang sistematis dalam keperawatan dibagi dalam empat tahap kegiatan, yang meliputi : pengumpulan data, analisa data, sistematika data dan penentuan masalah. Adapula yang menambahkannya dengan kegiatan dokumentasi data (meskipun setiap langkah dari proses keperawatan harus selalu didokumentasikan juga).

Pada tahap pengkajian ini telah dilakukan wawancara dan observasi kepada klien dimana didapatkan informasi tentang nama klien, umur, suku serta pendidikan terakhir. Pada pengkajian ini didapatkan bahwa Tn. J yang menderita TB Paru. Tn. J juga sering mengkonsumsi makanan berminyak dan hampir basi, pada saat berobat ke dokter, Tn. J berkonsultasi mengenai itu, Tn. J akhirnya tidak dianjurkan lagi makanan seperti itu. Semua data yang didapat ini merupakan gaya hidup yang tidak sehat, yang dapat menyebabkan infeksi TB Paru dalam tubuh meningkat. Dalam tahap ini klien telah memberikan informasi dalam pengumpulan data serta klien sudah mengetahui tujuan dari pengkajian yang dilakukan. Hal ini sangatlah sesuai dengan pendapat (Stanhope, 1989) dimana pada saat melakukan pengkajian perlu adanya tahap persiapan serta bagaimana melakukan pengkajian yang akhirnya bisa didapatkan suatu masalah. Dalam kegiatan yang telah dilakukan perlu adanya hubungan saling percaya dengan mahasiswa dalam pertemuan bersama.

Model keperawatan menurut Imogene King dikenal dengan pencapaian suatu tujuan. Model pencapaian suatu tujuan ini 
memberi pengertian bahwa keperawatan dengan menggunakan pendekatan system terbuka dalam hubungan interaksi yang konstan dengan lingkungan.

Pada pengkajian ini Tn. J merupakan klien dengan TB Paru menurut Teori King dipandang sebagai individu yang tidak memiliki kemampuan untuk mencapai suatu tujuan. Sehingga peran keluarga dan tenaga kesehatan disini sangatlah penting agar tercapainya kesehatan yang baik dan sejahtera dengan mengetahui tujuan perawatan yang akan dilakukannya. Oleh karena itu perawat menurut teori King berperan sebagai pendidik/pendukung bagi klien TB Paru untuk mencapai tujuannya yaitu penyembuhan kesehatan yang baik.

Ketidakseimbangan baik secara fisik maupun mental yang dialami Tn.J dengan TB Paru menurut King peran perawat dalam hal ini yaitu mengkaji klien sejauh mana klien mau untuk melakukan perawatan dalam pencapaian tujuannya untuk mengatasi batuk berdahak dadanya ketika batuk. Setelah pengkajian dan mendapatkan informasi yang lengkap barulah perawat mulai bekerja untuk membantu klien secara optimal sesuai dengan kondisi aktual klien yang berhubungan dengan TB Paru yang diderita oleh Klien untuk mengatasi batuk berdahak dadanya ketika batuk.

\section{Tahap Perumusan Diagnosa}

Menurut King, dalam tahap perumusan diagnosa didapatnya diagnosa keperawatan berdasarkan keputusan bersama antara perawat dan klien untuk mencapai tujuannya. Dimana dalam hal ini tujuannya yaitu untuk menghilangkan batuk berdahak pada penyakit TB Paru. Setelah didapatkan data dan informasi tentang keadaan kesehatan klien, maka didapatkanlah diagnosa keperawatan yaitu : "Ketidakefektifan kebersihan jalan nafas berhubungan dengan sekresi mucus yang kental". Sedangkan menurut Carpenito (1987) Diagnosa keperawatan adalah pernyataan yang menggambarkan respon manusia (keadaan sehat atau perubahan pola interaksi aktual atau potensial) dari individu atau kelompok perawata yang secara legal mengidentifikasi dan dimana perawat dapat menginstruksikan intervensi definitif untuk mempertanyakan keadaan sehat atau untuk mengurangi, menyingkirkan atau mencegah perubahan.

\section{Tahap Intervensi}

Menurut King intervensi yang dilakukan harus sesuai dengan keputusan bersama klien, dimana intervensi dilakukan untuk mencapai tujuan yaitu menghilangkan batuk berdahak pada TB Paru. Rencana asuhan keperawatan kepada Tn. J seperti mengajarkan Tn. J untuk batuk efektif, menganjurkan Tn. J untuk selalu minum air hangat kukuh di pagi hari dan menganjurkan Tn. J untuk minum obat yang teratur sesuai jadwalnya serta mengajari Tn. J untuk tidak meludah/membuang dahak tidak pada tempatnya yang telah disediakan. Intervensi yang diberikan adalah memberikan pendidikan yang mendukung untuk mengatasi batuk berdahak dan meningkatkan pengetahuan tentang penyakit TB Paru.

\section{PEMBAHASAN}

\section{Tahap Implementasi}

Menurut King, setelah disusun perencanaan yang telah disepakati oleh klien dan perawat, maka implementasi dapat dilakukan dari rencana tersebut. Implementasi dapat dilakukan dengan baik dimana telah direncanakan bersama-sama, maka didapatkan pula hasil yang baik, hal ini disebabkan adanya perencanaan yang matang serta adanya kesepakatan bersama dalam pelaksanaan kegiatan. Menurut teori King dijelaskan bahwa dalam melakukan suatu tindakan perlu adanya perumusan strategi dan berdasarkan keputusan bersama untuk kegiatan serta bagaimana agar tindakan yang kita lakukan mencapai suatu tujuan. Strategi yang digunakan yaitu pendidikan kesehatan, memberikan informasi tentang makanan pantangan untuk penyakit TB Paru dan terapi 
untuk mengatasi batuk berdahak

Implementasi yang telah dilakukan untuk dignosa Ketidakefektifan kebersihan jalan nafas berhubungan dengan sekresi mucus yang kental, Tn. J dianjurkan untuk batuk yang efektif, Tn. J dianjurkan untuk minum air hangat kukuh di pagi hari dan Tn. J dianjurkan untuk minum obat yang teratur sesuai jadwalnya serta Tn. J mampu untuk meludah / membuang dahak pada tempatnya yang telah disediakan. Berbeda halnya dengan pendapat Potter \& Perry (1997) Implementasi keperawatan adalah serangkaian kegiatan yang dilakukan oleh perawat untuk membantu klien dari masalah status kesehatan yang dihadapi kestatus kesehatan yang lebih baik yang menggambarkan kriteria hasil yang diharapkan Gordon (1994). Untuk kesuksesan pelaksanaan implementasi keperawatan agar sesuai dengan rencana keperawatan, perawat harus mempunyai kemampuan kognitif (intelektual), kemampuan dalam hubungan interpersonal dan keterampilan dalam melakukan tindakan. Proses pelaksanaan implementasi harus berpusat kepada kebutuhan klien, faktor-faktor lain yang mempengaruhi kebutuhan keperawatan, strategi implementasi keperawatan dan kegiatan komunikasi (Kozier et al, 1993).

\section{Tahap Evaluasi}

Menurut King adanya kerjasama dari klien maka mahasiswa dapat melakukan implementasi yang sebelumnya telah direncanakan, sehingga kegiatan yang dilakukan mahasiswa dapat diterima klien. Maka hasil evaluasi yang didapatkan pada diagnosa Ketidakefektifan kebersihan jalan nafas berhubungan dengan sekresi mucus yang kental, Tn. J bisa melakukan batuk yang efektif setiap harinya, Tn. J selalu minum air hangat kukuh di pagi hari, Tn. J selalu minum obat yang teratur sesuai jadwalnya serta Tn. J melakukan dengan sendirinya meludah / membuang dahak pada tempatnya yang telah disediakan. Menurut Craven dan Hirnle (2000) evaluasi didefenisikan sebagai keputusan dari efektifitas asuhan keperawatan antara dasar tujuan keperawatan klien yang telag ditetapkan dengan respon perilaku klien yang tampil.

\section{KESIMPULAN}

Dari hasil penelitian tentang Aplikasi Teori Model Imogene King tentang Motivasi Kesembuhan dengan Kepatuhan Minum Obat TB Paru pada Tn. J di Kelurahan Kandang RT. 06 di Wilayah Kerja Puskesmas Kandang Kota Bengkulu. Didapatkan bahwa Tn. J yang awalnya tidak mampu melakukan batuk efektif, sekarang sudah bisa melakukan batuk yang efektif setiap harinya, yang awalnya Tn. J tidak pernah minum air hangat kukuh di pagi hari, perlahan-lahan selalu minum air hangat kukuh di pagi hari, yang awalnya Tn. J tidak minum obat teratur bahkan lupa, sekarang selalu minum obat yang teratur sesuai jadwalnya serta Tn. J dapat melakukan dengan sendirinya meludah / membuang dahak pada tempatnya yang telah disediakan yang awalnya meludah / membuang dahak disembarang tempat. Sebagaimana dari Model Konsep menurut King, Interaksi sangat diperlukan karena bentuk kerja sama yang saling mempengaruhi antara perawat dan klien beserta keluarga agar terwujudnya komunikasi yang baik, sehingga asuhan keperawatan ini dapat dilakukan.

\section{SARAN}

Diharapkan penelitian ini dapat dijadikan sebagai sumber informasi dan kumpulan materi tentang perilaku Penderita TB Paru terhadap kepatuhan dalam hal minum obat sehingga motivasi kesembuhannya terus ada dan dapat mencegah resiko penularan penyakit TB Paru kepada anggota keluarga lainnya, serta dapat dijadikan objek penelitian lainnya dari aspek dan sudut pandang yang berbeda. 


\section{DAFTAR PUSTAKA}

Alimul Hidayat, A. Aziz. 2004. Pengantar Konsep Dasar Keperawatan. Jakarta: Salemba Medika

Amin, Zulkifli, dkk. 2007.Buku Ajar Ilmu Penyakit Dalam. Jilid II. Edisi IV.Jakarta: FKUI.

Carpenito, Lynda Juall. 2007. Buku Saku Diagnosis Keperawatan. Edisi 10. Dialih bahasakan oleh Yasmin Asih. Jakarta : EGC.

Depkes RI.2011. TBC Masalah Kesehatan Dunia. www.bppsdmk.depkes.go.id. Tanggal diakses : 20 Maret 2011.

Doenges, Marilynn E, et al. 2005. Nursing diagnosis manual: Planning, individualizing, and documenting client care.Philadelphia : F.A. Davis Company.

Judith M. Wilkinson dan Nancy R. Ahern. Buku Saku DIAGNOSIS KEPERAWATAN Diagnosis NANDA, Intervensi NIC, Kriteria hasil NOC Edisi 9. Alih Bahasa Ns. Esti Wahuningsih, S.Kep dan Ns. Dwi Widiarti, S,Kep. EGC. Jakarta.

NANDA International. 2002. Diagnosa keperawatan definisi dan klasifikasi 2009-2011.Dialih bahasakan oleh Made Sumarwati, dkk. Jakarta : EGC.

Nursalam. 2001. Proses dan Dokumentasi Keperawatan Konsep dan Praktik.

Price, Sylvia Anderson dan Lorraine McCarty Wilson. 2006. Patofisiologi Konsep Klinis Proses-Proses Penyakit. Dialih bahasakan oleh Brahm U Pendit, dkk. Jakarta : EGC.

Smeltzer, Suzanne C, dkk. 2002. Buku Ajar Keperawatan Medikal Bedah Brunner dan Suddarth. Volume 1. Edisi 8.Dialih bahasakan oleh Andry, dkk. Jakarta: EGC.

2002. Buku

Ajar Keperawatan Medikal Bedah Brunner dan Suddarth. Volume 1. Edisi 8. Dialih bahasakan oleh Andry, dkk. Jakarta: EGC.

Wilkonson, Judith M. 2007. Buku Saku Diagnosa Keperawatan. Dialih bahasakan oleh Widyawati, dkk. Jakarta : EGC 